Article

\title{
Production of Sorbitol via Catalytic Transfer Hydrogenation of Glucose
}

\author{
Beatriz García ${ }^{\circledR}$, Jovita Moreno ${ }^{\circledR}$, Gabriel Morales ${ }^{\circledR}$, Juan A. Melero and Jose Iglesias * \\ Chemical \& Environmental Engineering Group, Universidad Rey Juan Carlos, C/Tulipan s/n., E28933 Mostoles, \\ Madrid, Spain; beatriz.gsanchez@urjc.es (B.G.); jovita.moreno@urjc.es (J.M.); gabriel.morales@urjc.es (G.M.); \\ juan.melero@urjc.es (J.A.M.) \\ * Correspondence: jose.iglesias@urjc.es; Tel.: +34-914-888-565
}

Received: 14 February 2020; Accepted: 4 March 2020; Published: 7 March 2020

Featured Application: Catalytic transfer hydrogenation from alcohols allow converting under mild reaction conditions glucose into sorbitol.

\begin{abstract}
Sorbitol production from glucose was studied through catalytic transfer hydrogenation (CTH) over Raney nickel catalysts in alcohol media, used as solvents and hydrogen donors. It was found that alcohol sugars, sorbitol and mannitol, can be derived from two hydrogen transfer pathways, one produced involving the sacrificing alcohol as a hydrogen donor, and a second one involving glucose disproportionation. Comparison between short-chain alcohols evidenced that ethanol was able to reduce glucose in the presence of Raney nickel under neutral conditions. Side reactions include fructose and mannose production via glucose isomerization, which occur even in the absence of the catalyst. Blank reaction tests allowed evaluating the extension of the isomerization pathway. The influence of several operation parameters, like the temperature or the catalyst loading, as well as the use of metal promoters (Mo and Fe-Cr) over Raney nickel, was examined. This strategy opens new possibilities for the sustainable production of sugar alcohols.
\end{abstract}

Keywords: sorbitol; catalytic transfer hydrogenation; Raney nickel; glucose; biomass; catalysis

\section{Introduction}

Lignocellulose biomass is considered a promising alternative source to fossil fuels for the sustainable production of useful chemicals and value-added products [1,2]. The abundance of this feedstock makes biomass the only alternative to the traditional raw materials used in chemical industries, with most of them based on the exploitation of crude oil derivatives. Lignocellulose biomass is mainly composed of cellulose, hemicellulose, and lignin [3] - two polysaccharides (cellulose and hemicellulose), and a random polymer mainly composed of phenyl derivatives (lignin). Lignocellulosic biomass is the major component of agricultural waste and forest residue, which are inexpensive and abundant raw materials, as well as a primary source of monosaccharides, including glucose and fructose [4], which can be converted into a variety of different chemicals, including sugar polyols.

Sugar polyols are interesting monosaccharide-derived products, which find applications in several fields, both as polyols and as starting materials for the preparation of different products. Sorbitol is a sugar polyol extensively used in nutrition, cosmetics, and medical or industrial applications. It is employed as a low-calorie sweetener, as a humectant in cosmetics and pharmaceutical products, and as an intermediate platform for the production of value-added molecules (e.g., 1,4-sorbitan, isosorbide, glycols, L-ascorbic acid, etc.) [5-7]. This versatility led to its inclusion in the top derived value-added chemicals to be converted into high-value bio-based products from biomass [8]. 
Sorbitol production was reported to be carried out using cellulose in the presence of noble metals [9] and transition metal-based catalysts $[10,11]$. However, a most extended alternative is its production starting from glucose. At an industrial scale, sorbitol is produced via glucose hydrogenation [2] as it is the most affordable precursor [12], whose production is liable to be obtained via cellulose hydrolysis $[13,14]$. The reaction mechanism consists of the reduction of carbonyl groups of saccharides under hydrogen pressure in the presence of a solid metal catalyst based on $\mathrm{Ni}, \mathrm{Pd}, \mathrm{Pt}$, or $\mathrm{Ru}[15,16]$. All these catalysts are easily recoverable and display good catalytic activity in terms of sorbitol yield, operating under aqueous-phase solution [6,17-20]. In recent years, Raney nickel and ruthenium catalysts made a clean sweep on sorbitol production. Ru presents higher activity and selectivity to sorbitol $[16,21]$ than Raney nickel catalysts, but this metal is much more expensive than nickel-based catalysts. In this way, Raney nickel was revealed as the most interesting active phase to be used in the industrial-scale hydrogenation of glucose [21,22], mostly because of its low price [23]. Nevertheless, the lower catalytic activity of nickel as compared to other precious-metal-based conventional hydrogenation catalysts, such as ruthenium, results in the need for high hydrogen pressure and harsh operating conditions. Consequently, a significant energy demand must be satisfied compared to that required when using more active hydrogenation catalysts and, thus, higher environmental impacts are associated with the use of Raney nickel catalysts [24].

This work focuses on gaining insights into a developing alternative reaction pathway to the conventional hydrogenation procedure used to transform glucose into sorbitol by exploring the feasibility of carrying out the transformation through catalytic transfer hydrogenation (CTH) using a hydrogen donor. $\mathrm{CTH}$ is, a priori, a more sustainable alternative to conventional hydrogenation with molecular hydrogen because of the lower requirements for high-pressure conditions. CTH is usually performed in the presence of hydrogen donors, such as small alcohols and acids, which can be used under liquid phase conditions and under moderate operation conditions, and which are potentially easily prepared from renewable biomass feedstock [25-27].

Reduction of glucose to sorbitol via CTH is scarcely reported for catalysts based on $\mathrm{Pt}, \mathrm{Rh}$, or $\mathrm{Ru}[28,29]$, and only a few contributions focused on using nickel catalysts [29,30]. Thus, Scholz et al. [30] studied the CTH of glucose to sorbitol, in the presence of hydrotalcite-derived catalysts $\left(\mathrm{Cu}_{6-X} \mathrm{Ni}_{X} \mathrm{Al}_{2}\right)$, suggesting that Ni-based catalysts, such as Raney-type metal sponges could display notable catalytic activity in the CTH reduction of glucose. In previous work, we demonstrated that the use of the already industrially implemented Raney nickel catalysts is a good option to be used in a different operational procedure to that conventionally used for the ring-opening hydrogenation from glucose to sorbitol [31]. Within this context, the present work deals with the understanding of the behavior of several Raney nickel catalysts, as well as the influence of important operational parameters like the temperature conditions or the catalyst loading, in the production of sorbitol from glucose through a catalytic transfer hydrogenation mechanism, using short-chain alcohols as hydrogen donors.

\section{Materials and Methods}

\subsection{Materials}

D-Glucose ( $\geq 99.5 \%$ ), fructose ( $\geq 99 \%$ ), mannose ( $\geq 99 \%)$, sorbitol $(99 \%)$, and mannitol ( $\geq 98 \%)$ were purchased from Sigma-Aldrich (USA) and used without prior purification. A-4000, A-5000, and A-7063 sponge Nickel ${ }^{\mathrm{TM}}$ Catalyst were kindly provided by Johnson Matthey Process Technologies.

\subsection{Catalytic Tests}

The CTH catalytic tests were performed in a 100-mL stainless-steel batch reactor (Autoclave Engineers) fitted with a temperature controller, a mechanical stirrer, and a pressure transducer to monitor the reaction conditions. In a typical assay, $75 \mathrm{~mL}$ of a $90 \mathrm{mM}$ D-glucose alcohol solution was loaded in the reactor vessel together with an appropriate amount of Raney nickel catalyst. Before its use, the catalyst was suspended in the same alcohol used for the catalytic test and outgassed by sonication. 
The autoclave was then closed and fluxed with nitrogen to ensure inert conditions, and the temperature $\left(130-190^{\circ} \mathrm{C}\right)$ and stirring condition $(500 \mathrm{rpm})$ were set up. Autogenous pressure conditions were used in all the experiments; thus, operation was performed in the pressure range 9-26 bar, depending on the applied reaction temperature. Sample aliquots were periodically withdrawn from the reaction media to monitor the conversion of the substrate and the yield toward the different products. The reaction was cooled down with an ice water bath after $6 \mathrm{~h}$. The catalysts were recovered by simple filtration and washed with fresh solvent.

\subsection{Analysis of Products}

The analysis of the reaction products was performed using both HPLC and GC analyses. High-performance liquid-phase chromatography was performed in an Agilent 1260 Infinity unit coupled with evaporative light scattering and UV-diode array detectors. Product separations were performed using a Hi-Plex Ca, $300 \times 7.7 \mathrm{~mm}$ column, using water as the mobile phase at a flow rate of $0.6 \mathrm{~mL} \cdot \mathrm{min}^{-1}$ and operating at $80^{\circ} \mathrm{C}$. GC analysis was used for the quantification of volatiles such as the aldehydes coming from the dehydrogenation of the sacrificing alcohol. These assays were performed on a GC (Agilent) system fitted with a CP-WAX $57 \mathrm{CB}$ column $(\mathrm{L}=50 \mathrm{~m}, \mathrm{D}=0.25 \mathrm{~mm}$, film $=0.20 \mu \mathrm{m}$ ) and an FID detector. The catalytic result is shown either in terms of conversion of glucose/fructose $\left(X_{i}\right)$ or in terms of yields $\left(Y_{i}\right)$, calculated as follows:

$$
\begin{gathered}
X_{i}(\%)=\frac{[\mathrm{mol} \text { of } \mathrm{i} \text { loaded in the reactor }-\mathrm{mol} \mathrm{i} \text { in product }]}{[\mathrm{mol} \text { of } \mathrm{i} \text { loaded in the reactor }]} \cdot 100, \\
Y_{i}(\%)=\frac{[\mathrm{mol} \mathrm{i} \text { in product }]}{[\mathrm{mol} \text { of substrate loaded in the reactor }]} \cdot 100 .
\end{gathered}
$$

\section{Results and Discussion}

\subsection{Influence of Sacrificing Alcohol}

The capability of Raney nickel to drive the catalytic transfer hydrogenation of glucose to sorbitol was assessed using different short-chain alcohols as solvents and sacrificing alcohols. For this purpose, methanol, ethanol, and 2-propanol were used as potential hydrogen donors in the presence of a conventional nickel sponge catalyst. These alcohols were previously reported to be suitable hydrogen donors in different CTH reactions in the presence of nickel-based catalysts. Figure 1 depicts the results achieved (cumulative product yields and substrate conversion) in the transformation of glucose and fructose solutions prepared from the tested reaction solvents, treated in the presence of Raney nickel catalyst. The cumulative product yields and substrate conversion are depicted for all the tested short-chain alcohols. Substrate conversion was almost complete after reacting for $6 \mathrm{~h}$, regardless of the used solvent. The results from the blank test, which was accomplished by treating an aqueous solution of glucose in the absence of any hydrogen donor, but in water, revealed that this substrate can be transformed in the presence of Raney nickel catalysts into hexitols (sorbitol and mannitol) in quite a large extension. This behavior was previously described to occur because of the reducing capability of glucose, coming from its ability to donate a hydrogen molecule through the oxidation of the hydroxyl group located in the $\alpha$ position, thus leading to the formation of gluconolactone. $\mathrm{Th}_{2} \mathrm{H}_{2}$ molecule is then transferred, mediated by the nickel catalyst, to a different molecule of glucose, thus leading to the formation of sorbitol via ring-opening hydrogenation, in a sort of disproportionation transformation of glucose (one molecule is oxidized whereas another one is reduced). This phenomenon was previously described to occur in the presence of metal catalysts such as Pd [29] and, more recently, Ru [32]. Nevertheless, the auto reduction of glucose is not the only transformation taking place in the reaction medium as, together with sorbitol, mannitol, and fructose are also produced through side reaction pathways. Fructose is most probably produced by the isomerization of glucose, a transformation which can be mediated by the aluminum traces remaining in the catalysts after the preparation of 
the sponge-like catalysts (which account for more than 5\%) or simply because of a thermal effect. Mannitol, on the contrary, is not produced via the isomerization of sorbitol, but through (catalytic transfer) hydrogenation of fructose. All the detected chemical transformations are depicted in Scheme 1. The ring-opening hydrogenation of this monosaccharide produces, unlike in the case of glucose, two different hexitol isomers, sorbitol and mannitol, in equimolecular amounts, depending on which side of the sugar ring is approached by the nickel catalyst to be reduced.

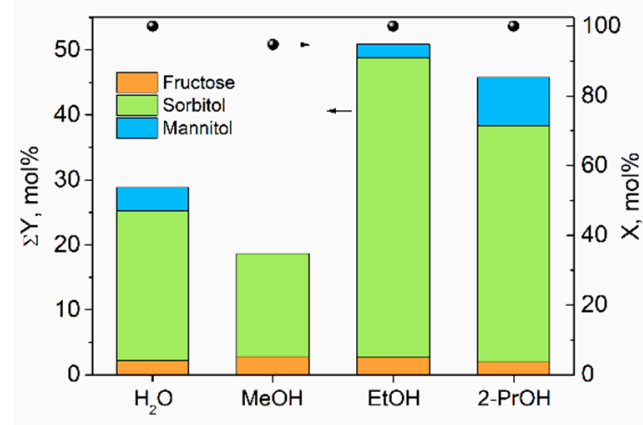

(a)

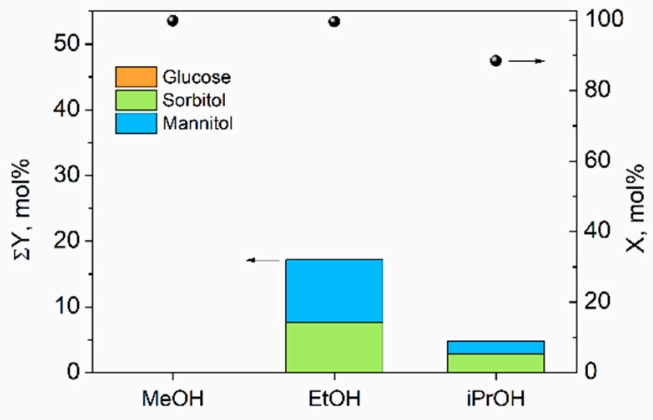

(b)

Figure 1. Cumulative product yields (left axes) and substrate conversion (right axes) in the catalytic transfer hydrogenation of (a) glucose and (b) fructose, with different solvents in the presence of Raney nickel catalysts. Reaction conditions: temperature $=150{ }^{\circ} \mathrm{C}$; substrate concentration $=90 \mathrm{mM}$; substrate to catalyst mass ratio $=1: 1$; reaction time $=6 \mathrm{~h}$.

As for the influence of the type of short-chain alcohol used as a hydrogen donor, results evidenced the formation of the same reaction products already described for the test performed in water. Large differences are evident between the product distributions achieved in the presence of each short-chain alcohol, showing that the alcohol media do exert an influence on the product distribution. Thus, methanol provided a substantially lower amount of hexitols as compared to ethanol or 2-propanol. In this case, the presence of highly stable methyl glucopyranosides was detected in the reaction media, coming from the etherification of the sugar monosaccharide in the $\alpha$ position with the alcohol solvent. This transformation avoids glucose undergoing dehydrogenative oxidation toward gluconolactone, depressing the extension of the sugar disproportionation and the consequent production of sorbitol. On the other hand, alkyl glucopyranosides were detected in trace levels when using ethanol and 2-propanol as hydrogen donors and reaction solvents. This is probably due to the better performance of ethyl and 2-propyl moieties as leaving groups, and the consequent lower stability of the resultant alkyl glucopyranosides under the tested reaction conditions. In this way, the achieved sorbitol yield in tests performed in the presence of different alcohols varies according to the following trend: ethanol > 2-propanol > methanol.

Unlike methanol, ethanol and 2-propanol provide sorbitol yield values higher than those obtained in aqueous phase conditions, suggesting the existence of a net contribution to the formation of sorbitol coming from the hydrogen transfer from these alcohol solvents to the sugar substrate. To assess this possibility, several additional experiments were performed. Firstly, the analysis of the reaction media using gas chromatography analysis confirmed the presence of acetaldehyde and acetone evolved during the dehydrogenation of ethanol and 2-propanol, respectively. On the contrary, formaldehyde was not detected, evidencing that, unlike for ethanol and 2-propanol, the catalytic transfer hydrogenation from methanol does not occur under the tested conditions. Secondly, several catalytic tests were also performed, this time under the very same reaction conditions as those already described for glucose, instead using fructose as the reaction substrate. Fructose, unlike glucose, cannot undergo disproportionation because the quaternary carbon at the furanose sugar ring cannot donate an $\mathrm{H}_{2}$ molecule. 
a)<smiles>OCC1OC(O)C(O)C(O)C1O</smiles>

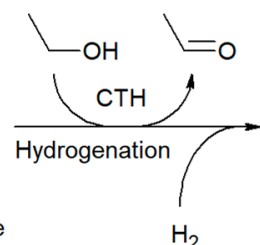<smiles>OCC(O)C(O)C(O)CO</smiles>

b)<smiles>OCC1OC(O)C(O)C(O)C1O</smiles>
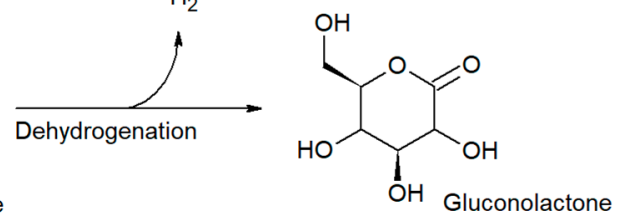

c)<smiles>OCC1OC(O)C(O)C(O)C1O</smiles>

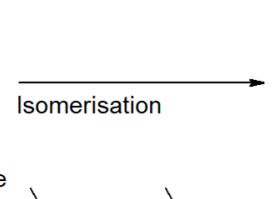<smiles>OCC1OC(O)(CO)C(O)C1O</smiles>

d)
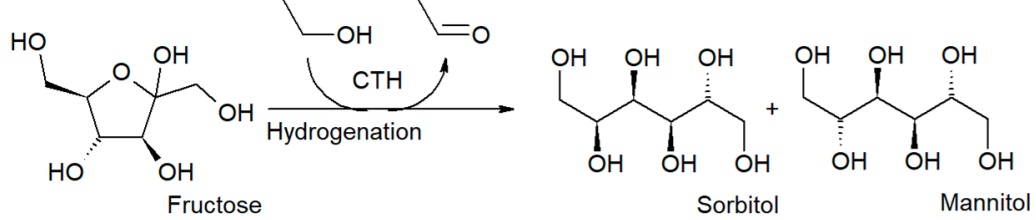

Scheme 1. Chemical transformations occurring when treating glucose in the presence of Raney nickel in alcohol media: (a) catalytic transfer hydrogenation from glucose to sorbitol, (b) glucose dehydrogenation to gluconolactone, (c) glucose isomerization to fructose, and (d) catalytic transfer hydrogenation from fructose to sorbitol and mannitol.

Thus, the reduction of fructose under the tested conditions should come from the catalytic hydrogen transfer from the sacrificing alcohol. Under these conditions, methanol only provided traces of hexitols, confirming that methanol is not a good option as a hydrogen donor for glucose CTH. On the contrary, both ethanol and 2-propanol led to quantifiable amounts of sorbitol and mannitol, present in almost equimolar amounts as that corresponding to the non-stereo controlled hydrogenation of fructose. Nevertheless, ethanol provided lower amounts of mannitol, probably as a consequence of the lower extent of isomerization reactions in the presence of this solvent. Furthermore, ethanol seems to be a better hydrogen donor than 2-propanol under the tested conditions, bearing in mind the higher hexitol yields obtained with the primary alcohol. This behavior is probably due to the neutral conditions used during the catalytic tests, which favor the dehydrogenation of primary alcohols over secondary ones [33]. The better performance of ethanol as a sacrificing alcohol as compared to methanol or 2-propanol introduces an additional advantage for the $\mathrm{CTH}$ reduction of glucose to sorbitol, which is the possibility to obtain ethanol from renewable biomass via fermentation through well-known industrially scaled processes.

\subsection{Influence of the Reaction Temperature and Catalyst Loading}

Blank reactions were performed to assess the different side reactions taking place in the absence of Raney nickel catalysts. These tests were performed in the temperature range $130-190^{\circ} \mathrm{C}$. Results are depicted in Figure 2. Regardless of the temperature, fructose and mannose were obtained even in the milder conditions, most probably coming from the isomerization of the starting glucose. The extension of these transformations increases as the temperature rises, although, at $190{ }^{\circ} \mathrm{C}$, lower yields toward both mannose and fructose were detected. This is probably related to the existence of sugar monosaccharide-consuming side reactions, such as the dehydration of glucose/fructose toward 5-hydroxymethyl furfural [34]. Finally, blank tests also served to confirm the true catalytic activity of nickel in the above-observed hydrogen transfer reduction from glucose to sorbitol, as, in the absence of the metal catalyst, no sorbitol was detected. 


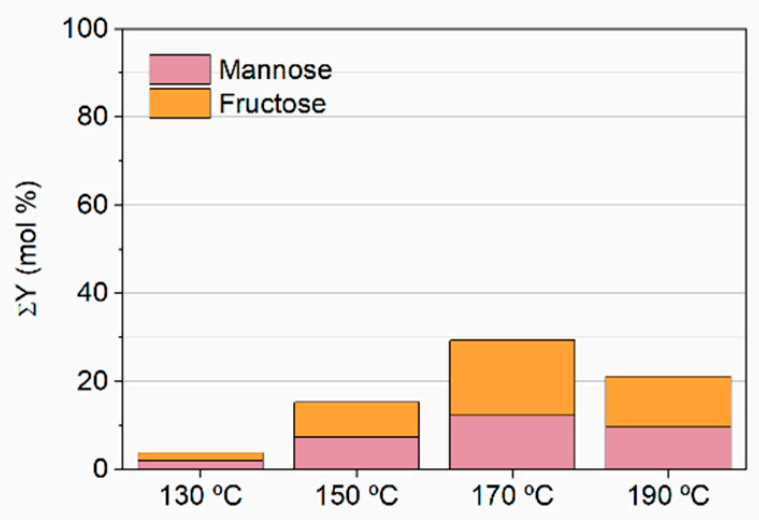

Figure 2. Cumulative product yields achieved in blank reactions performed at different temperatures. Reaction conditions: substrate concentration $=90 \mathrm{mM}$; reaction time $=6 \mathrm{~h}$.

The influence of several operational parameters (reaction temperature and catalyst loading) was assessed in the catalytic transfer hydrogenation of glucose to sorbitol, using ethanol as a sacrificing alcohol. Figure 3 depicts the product yields and substrate conversion achieved in the catalytic tests conducted at different temperatures, within the range $130-190^{\circ} \mathrm{C}$, and in the presence of two catalyst loadings (glucose to catalyst mass ratios $=8: 1$ and 1:1). The influence of both operation parameters on the glucose conversion rate was as expected, i.e., larger catalyst loading and temperature led to faster substrate conversion. As for product distribution, sorbitol was present as the main product in all tested conditions. However, the influence of the temperature and catalyst loading on the selectivity to the different products provided quite distinct results, as a consequence of a different effect of both operation parameters on the extension of not only the main reaction but also of the different side reactions taking place under the tested conditions.

The catalyst loading exerted a dramatic influence on the extension of glucose isomerization to fructose and mannose. Assays performed with a lower catalyst loading resulted in a poorer selectivity toward the desired sorbitol, and a large amount of side products, such as mannose and fructose, were observed (Figure 3a-d). This influence was even higher when increasing the applied temperature. Increasing the catalyst loading led to substantial suppression of the extension of sugar isomerization reactions, and only a limited production of fructose and mannose, below 10\% total yield, was observed, even in the highest-temperature conditions. These results, together with those achieved from the blank tests, confirmed that the conversion of glucose into its different isomers is, under the tested reactions conditions, a side transformation not related to the Raney nickel catalyst but to a thermal effect.

As for the production of sorbitol, the extension of the catalytic transfer hydrogenation of glucose to this hexitol seems to be highly dependent on the catalyst loading. Thus, a substrate to catalyst mass ratio of 8:1 provided a limited production of sorbitol, even in the highest tested temperature conditions, leading to sorbitol yields always below $25 \%$ of the starting glucose. Increasing the catalyst loading to a substrate to catalyst mass ratio of 1:1 led to much more efficient conversion of the sugar monosaccharide into sorbitol. This transformation was very efficient in the lowest tested temperature conditions $\left(130^{\circ} \mathrm{C}\right)$, and sorbitol yields around $60 \%$ were, thus, produced after reacting for $6 \mathrm{~h}$. Total carbon balance was, under these conditions, very high, and about $80 \%$ of the starting substrate could be quantified as different products after reacting for $6 \mathrm{~h}$. This result is strong evidence of the catalytic transfer hydrogenation mainly taking place from the sacrificing ethanol to sorbitol, not from the sugar disproportionation, and a confirmation of the high potential of CTH for the transformation of glucose into sorbitol using sacrificing alcohols. 


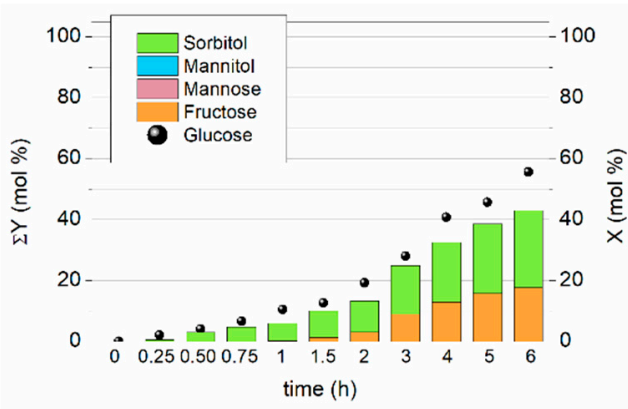

(a)

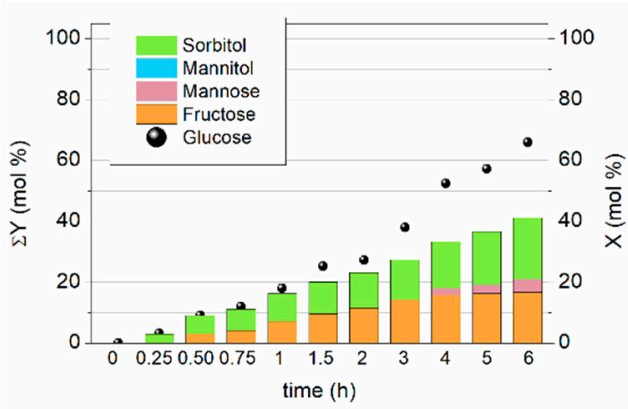

(b)

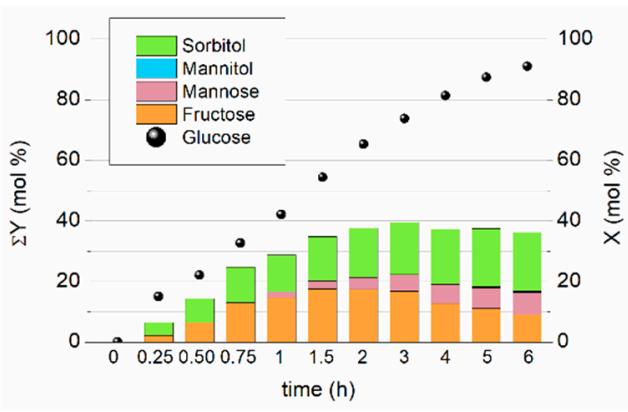

(c)

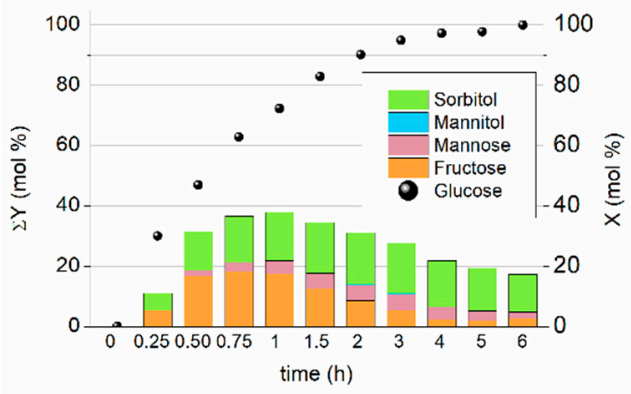

(d)

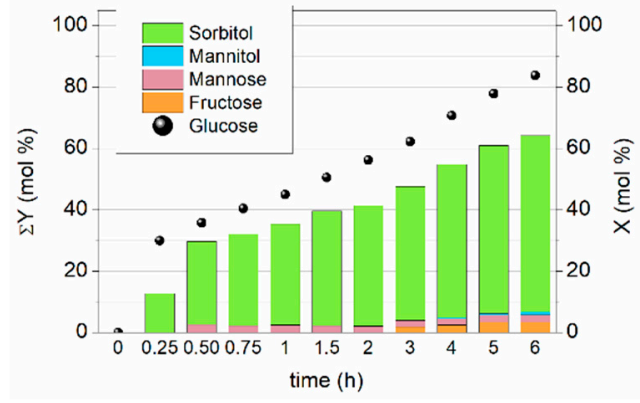

(e)

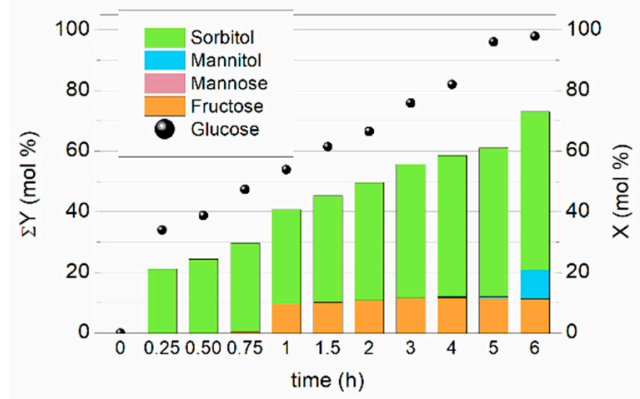

(f)

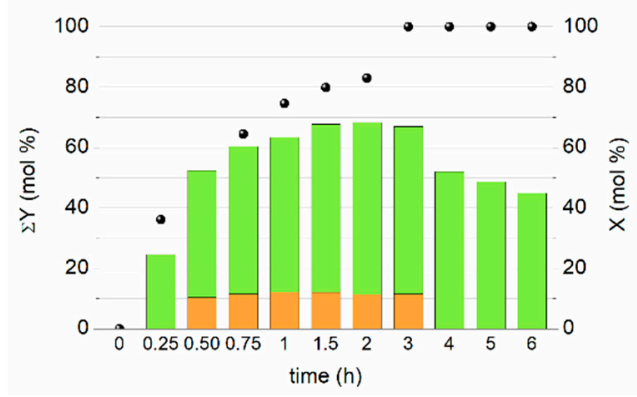

(g)

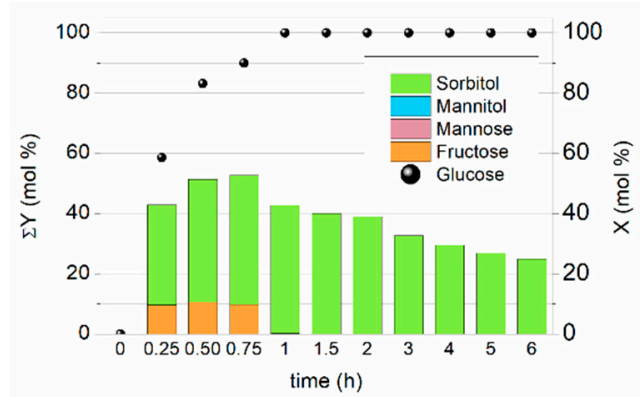

(h)

Figure 3. Cumulative product yields (bars, left axes) and substrate conversion (dots, right axes) achieved in the catalytic transfer hydrogenation of glucose in ethanol in the presence of Raney nickel catalyst with different substrate-to-catalyst weight ratios (1:8- left column, graphs a-d); (1:1—right column, graphs $\mathbf{e}-\mathbf{h})$. Reaction conditions: substrate concentration $=90 \mathrm{mM}$; reaction time $=6 \mathrm{~h}$; reaction temperature $=130{ }^{\circ} \mathrm{C}(\mathbf{a}, \mathbf{e}), 150{ }^{\circ} \mathrm{C}(\mathbf{b}, \mathbf{f}), 170{ }^{\circ} \mathrm{C}(\mathbf{c}, \mathbf{g})$, and $190{ }^{\circ} \mathrm{C}(\mathbf{d}, \mathbf{h})$. 
Increasing the reaction temperature led to, as stated above, acceleration of the substrate conversion, as well as diminishing sorbitol yields at long reaction times. The reasons for this phenomenon can be found in the enhancement of side reactions, such as sugar isomerization, as well as some other transformations related to the consumption of sorbitol, such as its hydrogenolysis. These side reactions usually take place in high-temperature conditions, such that these are highly influenced by a thermal effect. The transformations occur through the cleavage of sorbitol into different smaller polyols. The analysis of the liquid phase of the reaction media using GC allowed detecting some of the heavier products coming from these transformations, such as ethylene glycol, 1,2-propanediol, and glycerol.

\subsection{Influence of Catalyst Doping Agents}

Unlike for glucose hydrogenation, where extensive literature can be found, studies devoted to ascertaining the influence in CTH of different dopants in the catalytic activity of Raney-type nickel catalysts are not yet reported. Thus, this section is focused on evaluating the influence of typical metal promoters for Raney nickel catalysts, like $\mathrm{Fe}-\mathrm{Cr}$ and Mo (Table 1), on their ability to promote glucose conversion to sorbitol via CTH from ethanol. Nickel, like other metals from the VIII group, can interact with glucose through the carbonyl group, which is the basis of the catalytic activity of nickel in the hydrogenation of glucose. $\mathrm{Fe}-\mathrm{Cr}$ and Mo species in Raney nickel catalysts act as Lewis acid sites, providing oxophilicity to the catalyst $[15,22,35-37]$, and they modify the affinity of nickel for the $\mathrm{C}=\mathrm{O}$ group, necessarily conditioning its activity in hydrogenation or hydrogen transfer reactions. Figure 4 depicts the kinetic profiles obtained in the conversion of glucose to sorbitol, as well as the evolution of side products, performed at $150{ }^{\circ} \mathrm{C}$, and in the presence of different Raney nickel catalysts (Table 1).

Table 1. Chemical composition of Raney nickel catalyst used in this work.

\begin{tabular}{cccccc}
\hline Catalogue \# & Ni (wt.\%) & Al (wt.\%) & Fe (wt.\%) & Mo (wt.\%) & Cr (wt.\%) \\
\hline A-5000 & 93.9 & 5.5 & - & - & - \\
A-7063 & 93.3 & 5.8 & - & 1.1 & - \\
A-4000 & 85.6 & 8.6 & 2.3 & - & 2.5 \\
\hline
\end{tabular}

The conversion of glucose in the presence of unpromoted Raney nickel catalyst (Figure 4a) reached $64.9 \%$ after reacting for $6 \mathrm{~h}$. Sorbitol evolved as the main product, together with small quantities of fructose. Fe-Cr-doped Raney nickel led to an almost identical profile for glucose conversion, maybe slightly faster during the early stages of the reaction (Figure $4 \mathrm{~b}$ ). However, this catalyst provided lower substrate conversion $(\sim 60 \%)$ than the unpromoted catalyst, probably as a consequence of a deactivation phenomenon, conventionally occurring on Fe-Cr-doped Raney nickel through the leaching of the dopant agents [22]. The achieved sorbitol yield was much lower in the presence of $\mathrm{Fe}-\mathrm{Cr}$-doped catalyst than in the unpromoted one and, thus, only $11.5 \%$ of the starting glucose was obtained as sorbitol. Interestingly, a major fraction of the evolving sorbitol was obtained during the early stages of the reaction (up to $1 \mathrm{~h}$ ), resulting in the concentration of this product becoming almost constant during the rest of the reaction. This low amount of sorbitol was accompanied by the evolution of fructose, which was produced after the first hour, reaching yield values around $10 \%-15 \%$. This poor performance of the $\mathrm{Ni}-\mathrm{Cr}$-doped catalyst seems to be related to the leaching of the iron and chromium species and their dissolution in the solvent of the reaction [22]. Iron and chromium act as hydrogenation promoters for nickel, but their lixiviation eliminates their capacity to bind glucose molecules to the surface of the catalyst, although their Lewis acid features remain intact. In this way, the leached, Lewis acid Cr and Fe species do not promote catalytic transfer hydrogenation, but the isomerization of glucose to fructose $[38,39]$, which seems to become the dominant reaction after the first hour. Fructose is, unlike glucose, a substrate more resistant to undergoing CTH and, thus, only scarce evolution of sorbitol was detected after its production. The different kinetic profiles achieved for the products obtained in the presence of the $\mathrm{Fe}-\mathrm{Cr}$-promoted catalyst suggest that the deactivation of this material occurred during the first hour of the catalytic test. 
The molybdenum-promoted Raney nickel displayed a completely different catalytic performance to that shown by the Fe-Cr-doped material. In this case, a faster and more selective transformation of glucose into sorbitol was observed (glucose conversion of $\sim 78.5 \%$ and sorbitol yield of $38.4 \%$ ). Interestingly, low amounts of fructose were observed during the overall reaction test $(<6 \%)$, suggesting that, despite the Lewis acid features shown by molybdenum sites, its catalytic activity in glucose isomerization seems quite limited, and the beneficial influence of this metal on the capability of nickel to promote CTH becomes dominant.

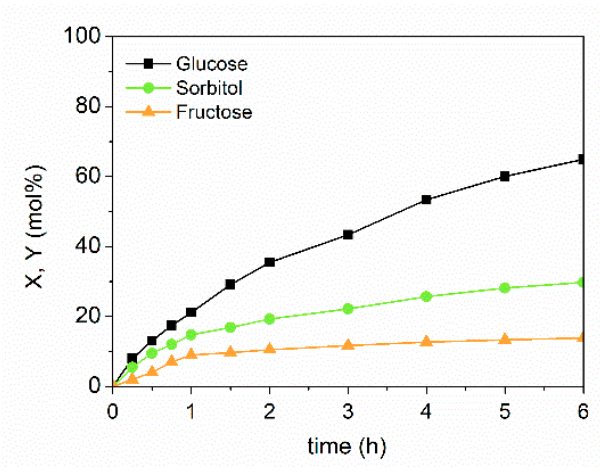

(a)

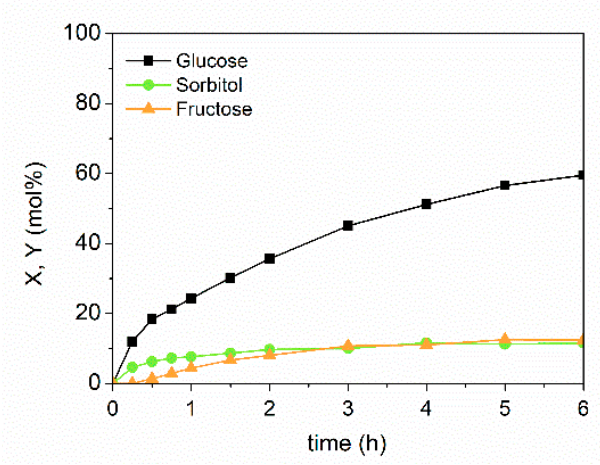

(b)

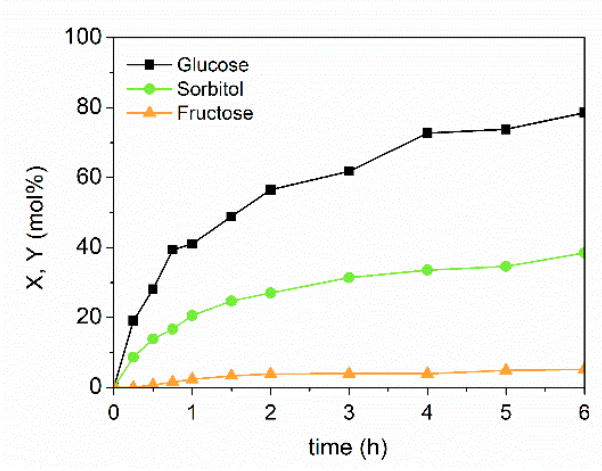

(c)

Figure 4. Kinetic profiles obtained for glucose conversion to sorbitol in the presence of Raney nickel type catalysts in ethanol: (a) unpromoted Raney nickel, (b) Fe-Cr-promoted Raney nickel, and (c) Mo-promoted Raney nickel. Reaction conditions: [glucose] $=90 \mathrm{mM}$, catalyst to substrate weight ratio $=1: 4$; reaction temperature $=150^{\circ} \mathrm{C}$. 
This better performance of Mo as compared to $\mathrm{Fe}-\mathrm{Cr}$ dopants seems to be related to its stability in the catalyst, something that can be ascertained from the negligible amount of leached Mo detected in the reaction media after the catalytic tests. In this way, the influence of Mo dopant is interpreted based on its capacity to bind glucose to the metal surface. Its oxophilicity leads to the interaction with the aldehyde group of glucose and, thus, an upward configuration is assumed for the carbonyl group, in which the $\eta 1(\mathrm{O})$ adsorbed species is formed by the donation of a lone electron pair from the oxygen atom at the $\mathrm{C}=\mathrm{O}$ group to the molybdenum atom. As a result, the $\mathrm{C}=\mathrm{O}$ bond gets polarized and the carbon atom can undergo a nucleophilic attack from a hydride group located at adjacent nickel atoms, thus leading to its reduction [22,40]. Hydride groups can be formed via the dehydrogenation of the sacrificing alcohol anywhere over the surface of the Raney nickel catalysts, before migrating through a spillover effect to the CHT sites. These results prompt Mo-promoted Raney-nickel catalysts as a promising selective catalyst for the catalytic transfer hydrogenation of glucose to sorbitol.

\section{Conclusions}

The production of sorbitol via catalytic transfer hydrogenation with Raney nickel catalysts was evaluated using short-chain alcohols as hydrogen donors. The comparative study of the performance shown using different sacrificing alcohols demonstrated ethanol as the best hydrogen donor under the tested conditions. This implies advantages from an environmental point of view, as the production of ethanol from biomass is an economic and technical feasible possibility. Moreover, glucose was proven to be able to undergo a disproportionation reaction, thus confirming that the production of sorbitol can be accomplished using self-reduction and catalytic transfer hydrogenation from the sacrificing alcohol. Catalyst loading was revealed as a key parameter conditioning the product distribution obtained when treating ethanolic solutions of glucose. High catalytic loadings enhanced the production of sorbitol, which, in combination with low-temperature conditions, led to the efficient transformation of glucose into sorbitol through the catalytic transfer hydrogenation pathway. Finally, the use of Raney nickel catalysts doped with different promoters is another factor liable to be used to enhance the yield to sorbitol. The use of molybdenum-doped Raney nickel catalyst exerts a beneficial effect, favoring the stability of nickel and enhancing the reduction of glucose to sorbitol.

Author Contributions: Conceptualization, J.I. and J.M.; methodology, B.G.; validation, G.M. and J.A.M.; formal analysis, J.I.; investigation, B.G.; writing-original draft preparation, B.G. and J.I.; writing-review and editing, J.M., G.M., J.A.M., and J.I.; supervision, J.M. and J.I.; project administration, G.M., J.A.M., and J.I.; funding acquisition, G.M., J.A.M., and J.I. All authors read and agreed to the published version of the manuscript.

Funding: This research was funded by the Spanish Ministry of Science, Innovation and Universities (project RTI2018-094918-B-C42) and by the Regional Government of Madrid (project BIOTRES-CM P2018/EMT-4344).

Acknowledgments: B. García kindly acknowledges the Regional Government of Madrid for a research contract (PEJD-2016/AMB-2321) funded through the European Social Fund. Johnson Matthey Process Technologies Co. is kindly acknowledged for providing the Raney nickel catalysts used in this investigation.

Conflicts of Interest: The authors declare no conflicts of interest.

\section{References}

1. Murillo Leo, I.; López Granados, M.; Fierro, J.L.G.; Mariscal, R. Selective conversion of sorbitol to glycols and stability of nickel-ruthenium supported on calcium hydroxide catalysts. Appl. Catal. B Environ. 2016, 185, 141-149. [CrossRef]

2. Romero, A.; Alonso, E.; Sastre, Á.; Nieto-Márquez, A. Conversion of biomass into sorbitol: Cellulose hydrolysis on MCM-48 and d-Glucose hydrogenation on Ru/MCM-48. Microporous Mesoporous Mater. 2016, 224, 1-8. [CrossRef]

3. Kumar, P.; Barrett, D.M.; Delwiche, M.J.; Stroeve, P. Methods for Pretreatment of Lignocellulosic Biomass for Efficient Hydrolysis and Biofuel Production. Ind. Eng. Chem. Res. 2009, 48, 3713-3729. [CrossRef]

4. Patil, C.R.; Rode, C.V. Synthesis of diesel additives from fructose over PWA/SBA-15 catalyst. Fuel 2018, 217, 38-44. [CrossRef] 
5. Robinson, J.M.; Wadle, A.M.; Reno, M.D.; Kidd, R.; Barrett Hinsz, S.R.; Urquieta, J. Solvent- and Microwave-Assisted Dehydrations of Polyols to Anhydro and Dianhydro Polyols. Energy Fuels 2015, 29, 6529-6535. [CrossRef]

6. Zada, B.; Chen, M.; Chen, C.; Yan, L.; Xu, Q.; Li, W.; Guo, Q.; Fu, Y. Recent advances in catalytic production of sugar alcohols and their applications. Sci. China Chem. 2017, 60, 853-869. [CrossRef]

7. Zhang, J.; Li, J.B.; Wu, S.B.; Liu, Y. Advances in the Catalytic Production and Utilization of Sorbitol. Ind. Eng. Chem. Res. 2013, 52, 11799-11815. [CrossRef]

8. Bozell, J.J.; Petersen, G.R. Technology development for the production of biobased products from biorefinery carbohydrates-The US Department of Energy's “Top 10" revisited. Green Chem. 2010, 12, 539-554. [CrossRef]

9. Fukuoka, A.; Dhepe, P.L. Catalytic Conversion of Cellulose into Sugar Alcohols. Angew. Chem. Int. Ed. 2006, 45, 5161-5163. [CrossRef]

10. Ji, N.; Zhang, T.; Zheng, M.; Wang, A.; Wang, H.; Wang, X.; Chen, J.G. Direct Catalytic Conversion of Cellulose into Ethylene Glycol Using Nickel-Promoted Tungsten Carbide Catalysts. Angew. Chem. Int. Ed. 2008, 47, 8510-8513. [CrossRef]

11. Van de Vyver, S.; Geboers, J.; Dusselier, M.; Schepers, H.; Vosch, T.; Zhang, L.; Van Tendeloo, G.; Jacobs, P.A.; Sels, B.F. Selective Bifunctional Catalytic Conversion of Cellulose over Reshaped Ni Particles at the Tip of Carbon Nanofibers. ChemSusChem 2010, 3, 698-701. [CrossRef] [PubMed]

12. Singh, H.; Rai, A.; Yadav, R.; Sinha, A.K. Glucose hydrogenation to sorbitol over unsupported mesoporous $\mathrm{Ni} / \mathrm{NiO}$ catalyst. Mol. Catal. 2018, 451, 186-191. [CrossRef]

13. Hausoul, P.J.C.; Beine, A.K.; Neghadar, L.; Palkovits, R. Kinetics study of the Ru/C-catalysed hydrogenolysis of polyols-Insight into the interactions with the metal surface. Catal. Sci. Technol. 2017, 7, 56-63. [CrossRef]

14. Li, J.; Soares, H.S.; Moulijn, J.A.; Makkee, M. Simultaneous hydrolysis and hydrogenation of cellobiose to sorbitol in molten salt hydrate media. Catal. Sci. Technol. 2013, 3, 1565-1572. [CrossRef]

15. Hoffer, B.W.; Crezee, E.; Mooijman, P.R.M.; van Langeveld, A.D.; Kapteijn, F.; Moulijn, J.A. Carbon supported $\mathrm{Ru}$ catalysts as promising alternative for Raney-type $\mathrm{Ni}$ in the selective hydrogenation of d-glucose. Catal. Today 2003, 79-80, 35-41. [CrossRef]

16. van Gorp, K.; Boerman, E.; Cavenaghi, C.V.; Berben, P.H. Catalytic hydrogenation of fine chemicals: Sorbitol production. Catal. Today 1999, 52, 349-361. [CrossRef]

17. Li, Z.; Liu, Y.; Wu, S. Efficient Conversion of D-Glucose into D-Sorbitol over Carbonized Cassava Dregs-Supported Ruthenium Nanoparticles Catalyst. BioResources 2018, 13, 1278-1288. [CrossRef]

18. Ribeiro, L.S.; Órfão, J.J.; Pereira, M.F.R. Comparative study of different catalysts for the direct conversion of cellulose to sorbitol. Green Process. Synth. 2015, 4, 71-78. [CrossRef]

19. Yamaguchi, A.; Sato, O.; Mimura, N.; Shirai, M. Catalytic production of sugar alcohols from lignocellulosic biomass. Catal. Today 2016, 265, 199-202. [CrossRef]

20. Zhang, X.; Durndell, L.J.; Isaacs, M.A.; Parlett, C.M.A.; Lee, A.F.; Wilson, K. Platinum-Catalyzed Aqueous-Phase Hydrogenation of d-Glucose to d-Sorbitol. ACS Catal. 2016, 6, 7409-7417. [CrossRef]

21. Aho, A.; Roggan, S.; Eränen, K.; Salmi, T.; Murzin, D.Y. Continuous hydrogenation of glucose with ruthenium on carbon nanotube catalysts. Catal. Sci. Technol. 2015, 5, 953-959. [CrossRef]

22. Gallezot, P.; Nicolaus, N.; Flèche, G.; Fuertes, P.; Perrard, A. Glucose Hydrogenation on Ruthenium Catalysts in a Trickle-Bed Reactor. J. Catal. 1998, 180, 51-55. [CrossRef]

23. Zhang, J.; Wu, S.; Liu, Y.; Li, B. Hydrogenation of glucose over reduced $\mathrm{Ni} / \mathrm{Cu} / \mathrm{Al}$ hydrotalcite precursors. Catal. Commun. 2013, 35, 23-26. [CrossRef]

24. Gericke, D.; Ott, D.; Matveeva, V.G.; Sulman, E.; Aho, A.; Murzin, D.Y.; Roggan, S.; Danilova, L.; Hessel, V.; Loeb, P.; et al. Green catalysis by nanoparticulate catalysts developed for flow processing? Case study of glucose hydrogenation. RSC Adv. 2015, 5, 15898-15908. [CrossRef]

25. Bulushev, D.A.; Ross, J.R. Towards Sustainable Production of Formic Acid. ChemSusChem 2018, 11, 821-836. [CrossRef]

26. Sarkar, N.; Ghosh, S.K.; Bannerjee, S.; Aikat, K. Bioethanol production from agricultural wastes: An overview. Renew. Energy 2012, 37, 19-27. [CrossRef]

27. Gilkey, M.J.; Xu, B. Heterogeneous Catalytic Transfer Hydrogenation as an Effective Pathway in Biomass Upgrading. ACS Catal. 2016, 6, 1420-1436. [CrossRef] 
28. Komanoya, T.; Kobayashi, H.; Hara, K.; Chun, W.-J.; Fukuoka, A. Simultaneous formation of sorbitol and gluconic acid from cellobiose using carbon-supported ruthenium catalysts. J. Energy Chem. 2013, 22, $290-295$. [CrossRef]

29. van Hengstum, A.J.; Kieboom, A.P.G.; van Bekkum, H. Catalytic Transfer Hydrogenation of Glucose-Fructose Syrups in Alkaline Solution. Starch Stärke 1984, 36, 317-320. [CrossRef]

30. Scholz, D.; Aellig, C.; Mondelli, C.; Pérez-Ramírez, J. Continuous Transfer Hydrogenation of Sugars to Alditols with Bioderived Donors over Cu-Ni-Al Catalysts. ChemCatChem 2015, 7, 1551-1558. [CrossRef]

31. García, B.; Moreno, J.; Iglesias, J.; Melero, J.A.; Morales, G. Transformation of Glucose into Sorbitol on Raney Nickel Catalysts in the Absence of Molecular Hydrogen: Sugar Disproportionation vs. Catalytic Hydrogen Transfer. Top. Catal. 2019, 62, 570-578. [CrossRef]

32. Kobayashi, H.; Matsuhashi, H.; Komanoya, T.; Hara, K.; Fukuoka, A. Transfer hydrogenation of cellulose to sugar alcohols over supported ruthenium catalysts. Chem. Commun. 2011, 47, 2366-2368. [CrossRef]

33. Chaloner, P.A.; Esteruelas, M.A.; Joo, F.; Oro, L. Homogeneous Hydrogenation; Kluwer Academic Publishers: Dordrecht, The Netherlands, 1994; Volume 15.

34. Jing, Q.; LÜ, X. Kinetics of Non-catalyzed Decomposition of Glucose in High-temperature Liquid Water. Chin. J. Chem. Eng. 2008, 16, 890-894. [CrossRef]

35. Hoffer, B.W.; Crezee, E.; Devred, F.; Mooijman, P.R.M.; Sloof, W.G.; Kooyman, P.J.; van Langeveld, A.D.; Kapteijn, F.; Moulijn, J.A. The role of the active phase of Raney-type Ni catalysts in the selective hydrogenation of d-glucose to d-sorbitol. Appl. Catal. A Gen. 2003, 253, 437-452. [CrossRef]

36. Cerino, P.J.; Fleche, G.; Gallezot, P.; Salome, J.P. Activity and Stability of Promoted Raney-Nickel Catalysts in Glucose Hydrogenation. In Studies in Surface Science and Catalysis; Guisnet, M., Barrault, J., Bouchoule, C., Duprez, D., Pérot, G., Maurel, R., Montassier, C., Eds.; Elsevier: Amsterdam, The Netherlands, 1991; Volume 59, pp. 231-236.

37. Court, J.; Damon, J.P.; Masson, J.; Wierzchowski, P. Hydrogenation of Glucose with Bimetallic Catalysts (NiM) of Raney Type. In Studies in Surface Science and Catalysis; Guisnet, M., Barrault, J., Bouchoule, C., Duprez, D., Montassier, C., Pérot, G., Eds.; Elsevier: Amsterdam, The Netherlands, 1988; Volume 41, pp. 189-196.

38. Delidovich, I.; Palkovits, R. Catalytic Isomerization of Biomass-Derived Aldoses: A Review. ChemSusChem 2016, 9, 547-561. [CrossRef]

39. Caratzoulas, S.; Davis, M.E.; Gorte, R.J.; Gounder, R.; Lobo, R.F.; Nikolakis, V.; Sandler, S.I.; Snyder, M.A.; Tsapatsis, M.; Vlachos, D.G. Challenges of and Insights into Acid-Catalyzed Transformations of Sugars. J. Phys. Chem. C 2014, 118, 22815-22833. [CrossRef]

40. Noller, H.; Lin, W.M. Effect of additives upon Raney-Nickel alloy catalysts. React. Kinet. Catal. Lett. 1982, 21, 479-483. [CrossRef]

(C) 2020 by the authors. Licensee MDPI, Basel, Switzerland. This article is an open access article distributed under the terms and conditions of the Creative Commons Attribution (CC BY) license (http://creativecommons.org/licenses/by/4.0/). 